\title{
Actual-time modeling of a subway vehicle and optimal driving management with $\mathrm{GA}$ and $\mathrm{ABC}$ algorithms
}

\author{
Yağmur arikan*, Tolga Şen** and Ertuğrul Çam*** \\ * Department of Information Systems and Technology, Sivas Cumhuriyet University, Sivas, Turkey \\ ** Department of Electric and Electronic Engineering, Krrlkkale University, Turkey \\ *** Department of Electric and Electronic Engineering, Samsun University, , Turkey. \\ *Corresponding Author: yagmurarikan@gmail.com
}

$\begin{array}{ll}\text { Submitted } & : 10 / 04 / 2020 \\ \text { Revised } & : 22 / 08 / 2021 \\ \text { Accepted } & : 06 / 09 / 2021\end{array}$

\begin{abstract}
The optimization of operations of subway systems has critical importance in terms of energy efficiency and costs. Therefore, driving management of subway vehicles has been gaining more importance day by day. Optimal Driving Management (ODM) is the optimization of the velocity trajectory of a subway vehicle by considering operating conditions and travel time. In this study, the driving of a subway vehicle has been modeled dynamically with all parameters that affect driving. So, a realistic model has been prepared. Then, a new objective function has been proposed to reduce energy consumption by using the subway vehicle's acceleration and braking forces parameters for ODM. The Artificial Bee Colony algorithm (ABC) and Genetic algorithm (GA) have been used on the prepared model to determine the driving dynamics of the subway vehicle. The performance of the algorithms has been evaluated in the real line network, which has multiple stations with different characteristics. The energy consumption has been reduced by $10.47 \%$ in GA and $8.92 \%$ in $\mathrm{ABC}$ compared to the actual driving values. Moreover, the results of the study have been analyzed in terms of passenger comfort, cost, and emission values.
\end{abstract}

Keywords: Dynamic model; Energy efficiency; Energy consumption; Artificial bee colony algorithm; Genetic algorithm.

\section{INTRODUCTION}

The subway systems have increasing importance in metropolitan cities. These systems prevent traffic congestion and provide reliable and punctual transportation to people. However, the high energy consumption and energy costs of these systems have been seen as a threat to sustainable living and a clean environment. For example, the electricity consumption of metro rail systems in Ankara, the capital of Turkey, is 192,197.22 kWh per day. Besides, the amount of emissions due to electricity consumption is important in terms of the carbon quota in recent years. Considering the developing and increasing rail system networks day by day, there is an urgent need for energy efficiency in subway systems. 
Most of the energy efficiency studies in the literature have been focused on optimizing the operation of subway vehicles. The various mathematical and heuristic methods have been used for these studies. The optimal control techniques are one of the most common methods in the literature. Hoang et al. applied optimal control techniques by using a direct search algorithm under some simplifying assumptions and achieved a saving of 7.73\% (1975). The maximum principle of Pontryagin was applied for energy efficiency in some studies. An analytical solution of optimal control problem, investigation of equations to find the control change points, and integrated timetable optimization were carried out with different restrictions such as variable grade profile and speed limit (Liu et al., 2003 \& Su et al., 2013). Additionally, in other studies that used Dynamic Programming, the velocity trajectory of the vehicle was examined in a discrete-time, and the effects of different working times on energy consumption were calculated (Miyatake et al., 2010; Ghaviha et al., 2015). GA, which is one of the heuristic methods, was used to seek the approximate optimal coasting strategies (Yang et al., 2012) and control the coasting point during the defined target travel time (Kang, 2014). Also, Sequential Quadratic Programming was used in modeling of traction system (Mandic et al., 2011) and the determination of best driving regimes for different running times (Haramina et al., 2012). Searching of optimal velocity profile was carried out by using the Multi-Objective Particle Swarm OptimizationNondominated Sorting Genetic Algorithm (Bigharaz et al., 2014) and Simulated Annealing optimization algorithm (Rocha et al., 2018). In these studies, energy savings ranging from $5 \%$ to $26 \%$ have been achieved depending on the length of the line, the number of stations, target travel time, and the various restrictions on the line. Whatever method is used to reduce energy consumption in rail systems, the driving of the vehicle should be modeled. As a result of the literature review, in some models, it has been observed that the effects of some forces acting on the vehicle were neglected, linear changes were applied instead of nonlinear changes, or the study was carried out only on the straight test line. Considering the continuity and complexity of the system, the dynamic model of the system should be used to demonstrate the suitability and authenticity of the proposed method; that is, the instantaneous change of parameters affecting the vehicle should be considered. In this paper, for this purpose, the driving of a subway vehicle has been modeled dynamically by using Matlab software. The other issue, which can be seen as a deficiency in the literature, is objective functions. In general, travel time and energy consumption values were taken as input parameters, and the effects of different travel times on energy consumption were examined. However, it is known that energy consumption decreases as travel time increases, and an increase in travel time would be unfavorable for passengers. Therefore, for the proposed ODM, while travel time and energy consumption values have been optimized together as output parameters, the acceleration and braking forces have been selected as input parameters. Also, the limits of acceleration and braking forces have been chosen according to the actual engine parameters. For the optimization process, GA and $\mathrm{ABC}$ have been preferred. The reason for using GA is one of the three methods that give the best results in determining velocity trajectory (Brenna et al., 2016). The ABC algorithm was previously used in timetable optimization for the efficient use of regenerative energy (Liu et al., 2018), but not for this method. In this paper, the $\mathrm{ABC}$ algorithm has been preferred because it had not been tried, has simple parameters, and gives good results in different optimization problems. For the realistic results, the study not only has been carried out on the test line, but it has also been carried out on multiple stations with different characteristics of the Ankaray subway line (Ego, 2019). When the results of the article are compared with the actual driving results, there are two points that must attract attention. The first of these is that the increase in travel time can be compensated by the waiting times at the station. Second, it has been observed that energy consumption is approximately $10.5 \%$ in the GA, $9.0 \%$ in the ABC. The effects of the study's results on emission and country cost have been also examined, and positive contributions have been made in this regard.

\section{THE DYNAMIC MODEL OF VEHICLE DRIVING}

A subway vehicle's movement can be affected by many constantly changing parameters during its traveling from one station to another. These parameters can be classified into three main groups: vehicle parameters, location parameters, and operation parameters. The movement of a subway vehicle can be examined mainly by Newton's second law, and Equation (1) demonstrates this law, which is related to force, mass, and velocity (Lu, 2011). 
$\sum F=m \cdot(1+\lambda) \cdot \frac{\partial^{2} x}{\partial t^{2}}$

where $\mathrm{F}$ represents all different forces, $\mathrm{m}$ is mass of the vehicle, $\lambda$ is the coefficient associated with the rotating parts of the vehicle, $\mathrm{x}$ is the distance, and $\mathrm{t}$ is travel time. The forces acting on the vehicle are shown in Figure 1.

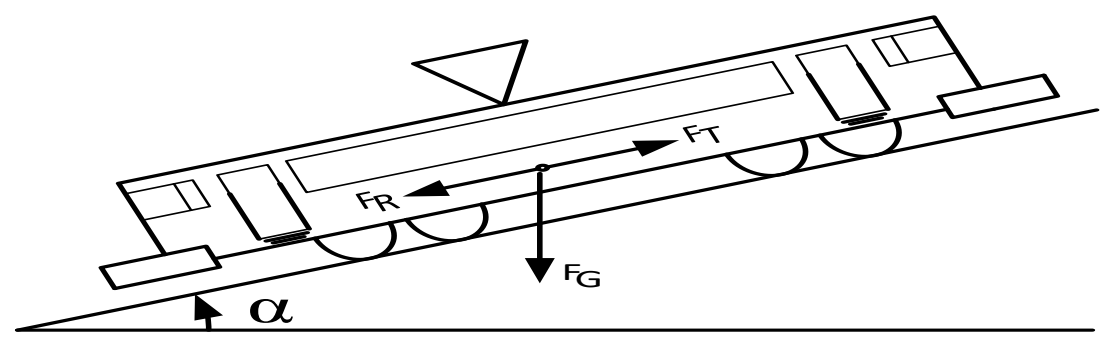

Figure 1. Different forces acting on the vehicle.

FT, FR, and FG represent tractive force (acceleration force-FA or braking force-FB), rolling resistance force, and gradient force, respectively (Rocha et al., 2018). FT is within specified limits according to engine parameters and takes different values depending on vehicle acceleration or braking regime, FR tries to prevent the movement of the vehicle, and FG occurs as the level changes in the track, and these can be calculated as follows:

$F_{T}=\frac{P \cdot \mathrm{y}}{v}$

$F_{R}=A+B \cdot v+C D \cdot v^{2}$

$F_{G}=m \cdot g \cdot \sin (a)$

where $\mathrm{P}$ is the power of the engine, $\eta$ is the efficiency in converting engine power to the tractive force, $\mathrm{v}$ is the velocity of the vehicle, $\mathrm{g}$ is the gravitational constant, and $\alpha$ is the angle of slope. Equation (3) is also referred to as the Davis Equation and depends on the velocity of the vehicle. B coefficient varies depending on the type of rail system and is accepted as 0.03 for locomotives and as 0.045 for passenger units. A and CD coefficients can be calculated as follows (Davis, 1926):

$A=1.3+\frac{29}{W}$

$C D=\frac{C \delta}{W M}$

where $\mathrm{W}$ is the axle weight in tons per axle of the locomotive, $\mathrm{M}$ is the number of the axles, $\delta$ is the crosssectional area of the locomotive in square feet, $\mathrm{C}$ is the streamlining coefficient, and this coefficient is accepted as 0.0024 for locomotives and as 0.00034 for passenger units (Davis, 1926). Apart from these forces, the other force $F_{C}$ 
is caused by curves and changes according to several factors. These factors can be parallelism between the wheelsets and the friction between wheel flanges and rail. This force can be calculated as follows (Brenna et al., 2016):

$F_{c}=m \cdot g \cdot \frac{d}{p-e}$

where $\mathrm{p}$ is the radius of the curve, and assume the following values for $\mathrm{d}$ and $\mathrm{e}$ :

i) $\quad \mathrm{d}=0.65 \mathrm{~m}$.

ii) $\quad \mathrm{e}=55 \mathrm{~m}$ (if $\mathrm{p}$ is greater than $350 \mathrm{~m}$ ).

iii) $\quad \mathrm{e}=65 \mathrm{~m}$, (if $\mathrm{p}$ is between 250 and $350 \mathrm{~m}$ ).

Equation (1) can be updated by adding the vehicle acceleration (a) and the basic dynamic laws (Rocha et al., 2018):

$\mathrm{a}=\frac{\partial v}{\partial t}=\frac{\partial^{2} x}{\partial t^{2}}=\frac{F_{T}-F_{R}-F_{G}-F_{C}}{m(1+\lambda)}$

The energy consumed during the movement of a railway vehicle can be calculated as follows (Lu, 2011):

$E=\int_{0}^{t} F_{T} \cdot v \cdot d t$

The most important factor affecting the vehicle's energy consumption is the vehicle's driving regime. These regimes are acceleration, cruise, coasting, and braking as shown in Figure 2 ( $\mathrm{Su}$ et al., 2013; Montrone et al.,2017).

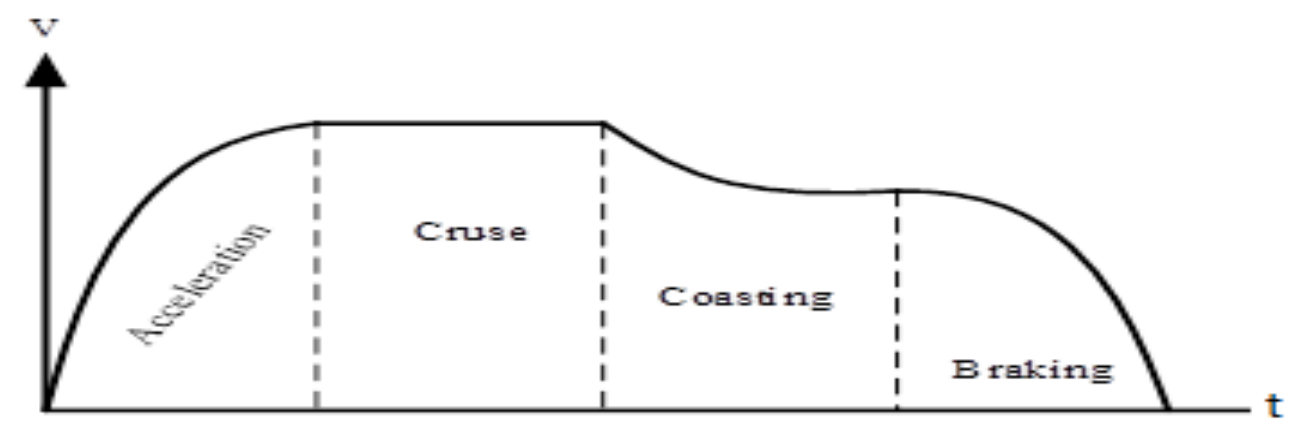

Figure 2. The driving regimes of the vehicle.

Acceleration: in general, the vehicle starts with this regime and continues until the maximum velocity limit. According to the optimal control theory, relevant equations are determined for all regimes. $u_{\mathrm{A}}$ and $\mathrm{u}_{\mathrm{B}}$ have been defined as control parameters for regimes, $\mathrm{F}_{\mathrm{A}-\mathrm{max}}$ is the maximum acceleration force, and $\mathrm{F}_{\mathrm{B}-\mathrm{max}}$ is the maximum braking force. In this regime:,

$$
\left\{\begin{array}{l}
F_{T}>F_{R}+F_{G}+F_{c} \\
u_{A}=\frac{F_{A}}{F_{A-\max }} \varepsilon[0,1] \\
u_{B}=\frac{F_{B}}{F_{B-\max }}=0
\end{array}\right.
$$


- Cruise: this regime can be realized in two ways: partial acceleration or partial braking. The velocity of the vehicle is constant in this regime.

$\left\{\begin{array}{l}F_{T}=F_{R}+F_{G}+F_{C} \\ u_{A} \varepsilon[0,1] ; u_{B}=0 \\ u_{A}=0 ; u_{B} \varepsilon[0,1]\end{array}\right.$

- Coasting: the mechanical energy is null, and the vehicle moves by inertia, and the coasting regime is important for energy consumption. In this regime,

$\left\{\begin{array}{c}F_{T}=0 ; F_{T}-F_{R}-F_{G}-F_{C}<0 \\ u_{A}=0 ; u_{B}=0\end{array}\right.$

- Braking: it is used to stop or decrease the velocity of the train at the desired point. Comfortable braking should be preferred for the passengers. In this regime,

$\left\{\begin{array}{c}F_{T}<0 ; F_{T}-F_{R}-F_{G}-F_{C}<0 \\ u_{A}=0 \\ u_{B} \in[0,1]\end{array}\right.$

In the study, a driving simulator software (DSS) hs been created, and while preparing this simulator, the equations given above have been converted from continuous time to separate time as follows:

$$
\left\{\begin{array}{c}
\Delta t=\frac{t}{N} \rightarrow i=0,1,2 \ldots N \\
\mathrm{a}_{i}=\frac{F_{T_{i}}-F_{R_{i}}-F_{G_{i}}-F_{C_{\mathrm{I}}}}{m(1+\lambda)} \\
v_{i+1}=v_{i}+\left(\mathrm{a}_{i} \cdot \Delta t\right) \\
x_{i+1}=x_{i}+\left(\frac{v_{i}+v_{i+1}}{2}\right) \cdot \Delta t \\
E_{i+1}=E_{i}+\left(F_{T_{i}} \cdot v_{i}\right) \cdot \Delta t \\
x_{f}=\frac{v_{f}^{2}}{2 \cdot \mathrm{a}_{f}}
\end{array}\right.
$$

where $\mathrm{t}, \Delta \mathrm{t}, \mathrm{i}$, and $\mathrm{N}$ represent the travel time, the step size, the number of steps, and the total number of steps. ai denotes acceleration at step $\mathrm{i}, \mathrm{V}_{\mathrm{i}+1}, \mathrm{x}_{\mathrm{i}+1}$, and $\mathrm{E}_{\mathrm{i}+1}$ velocity, distance, and the energy consumption at step $\mathrm{i}+1 . \mathrm{xf}_{\mathrm{f}} \mathrm{Vf}$, and af correspond to the safe stopping distance, current velocity of the vehicle, and braking acceleration. The diagram of the DSS is given in Figure 3. 


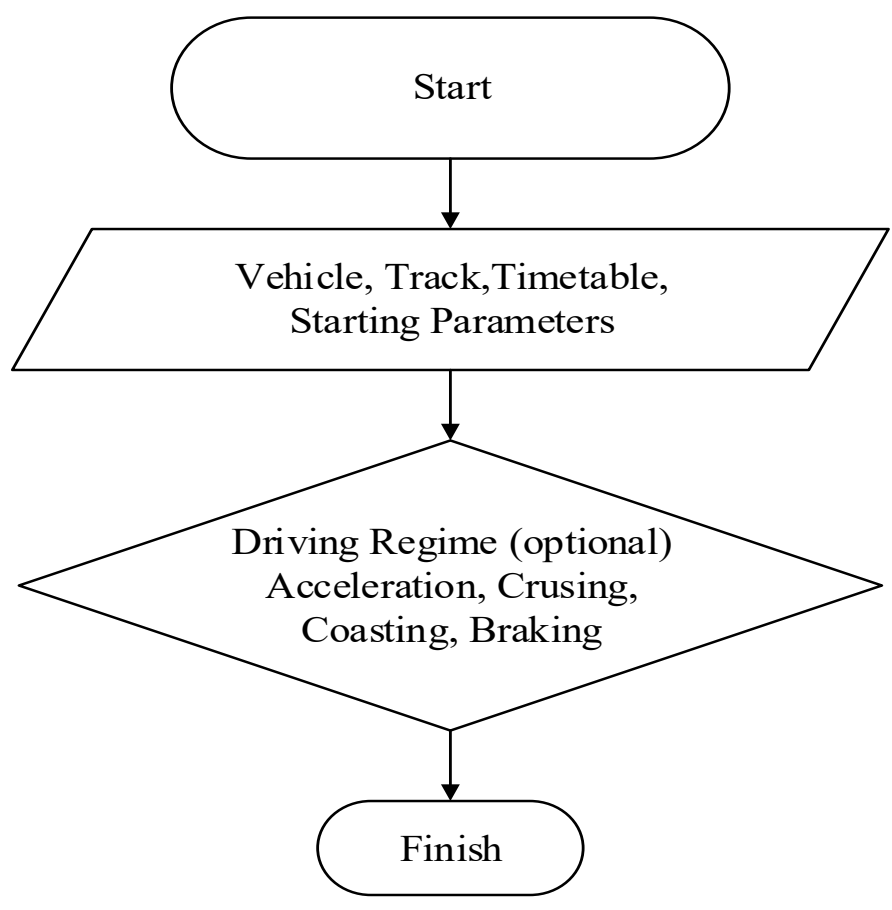

Figure 3. The schematic representation of DSS.

\section{OPTIMAL DRIVING MANAGEMENT (ODM)}

The purpose of this article is to drive the subway vehicle from the start station to the end station with minimal energy consumption without affecting the comfort of the passengers. Passengers do not like the increase in travel time. So, one of the most important factors affecting the comfort of passengers during travel is time. Therefore, while trying to reduce energy consumption, the increase in travel time has been minimized. The actual driving style of a metro vehicle has been tried to learn after the interviews with various subway companies. In reality, since these companies have no data recorded with electricity consumption and travel time, this driving has been modeled with DSS. Thus, the actual travel time and energy consumption values have been found and recorded with this model. After the modeling process, the optimization process has been started. In the literature, it has been seen that the input parameters are travel time and energy consumption. The most appropriate values have been selected from the various objective functions. However, since the increase in travel time generally reduces the energy consumption, and the comfort of the passengers is taken into consideration, acceleration and braking forces have been used as input parameters in this study. During the optimization process, if there is no other restriction, the driving consists of acceleration, coasting, and braking regimes. The accelerating $\left(\mathrm{F}_{\mathrm{a}}\right)$ and braking force $\left(\mathrm{F}_{\mathrm{b}}\right)$ of the vehicle engine have been operated at different values. Thus, maximum energy consumption $\left(E_{\max }\right)$, minimum energy consumption ( $\left.E_{\min }\right)$, maximum travel time $\left(t_{\max }\right)$, and minimum travel time $\left(t_{\min }\right)$ values have been found. The different travel time values have been compared with the actual values ( $\left.\mathrm{t}_{\text {act }}\right)$, and a penalty factor $(\mathrm{pf})$ has been determined as 1.01 for delays up to $2.5 \%$ and as 1.05 for delays greater than $2.5 \%$. Accordingly, ODM of the subway vehicle can be described as 


$$
\left\{\begin{array}{c}
F_{A-\min } \leq F_{A} \leq F_{A-\max } \\
F_{B-\min } \leq F_{B} \leq F_{B-\max } \\
v(0)=0 ; v(N)=0 \\
x(0)=0 ; x(N)=x \\
0 \leq v(i) \leq v_{\max } \\
f\left(F_{A}, F_{B}\right) \rightarrow v, x, t, E \\
p_{f}=1.01 \rightarrow t \leq \text { tact. } 1.025 \\
p_{f}=1.05 \rightarrow t \geq \text { tact. } 1.025 \\
E_{o p}=E . p_{f} \rightarrow t_{o p} \\
O D M=\left(E_{o p}, t_{o p}\right) \\
E_{\min } \leq E_{o p} \leq E_{\max } \\
t_{\min } \leq t_{o p} \leq t_{\max }
\end{array}\right.
$$

GA and $\mathrm{ABC}$ have been used for optimization in the paper. The diagram of the optimization process is shown in Figure 4. The algorithms are described in detail below.

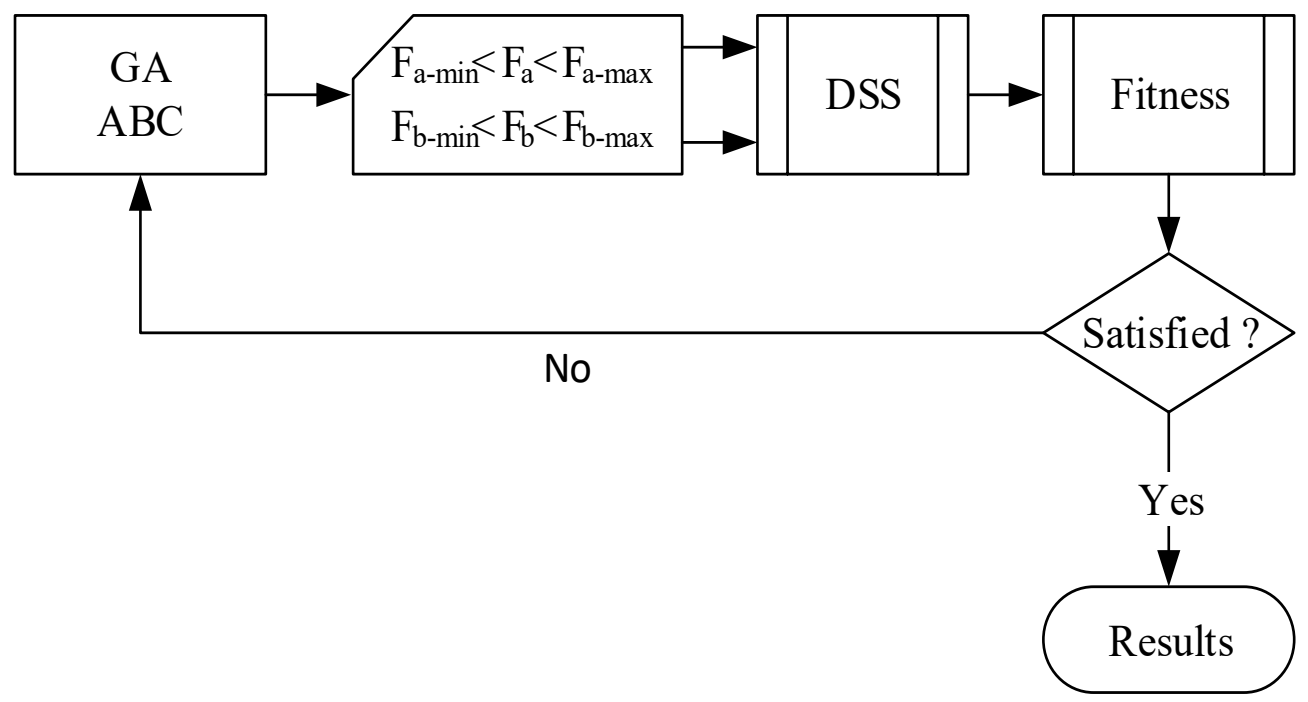

Figure 4. The diagram of the optimization process.

\section{Genetic Algorithm and Artificial Bee Colony Algorithm}

GA was first described by John Holland from the University of Michigan during his study of machine learning in 1975. The flowchart of this algorithm is given in Figure 5 (Hermawanto, 2019). ABC is an algorithm based on the smart behaviours of honey bees and was first described by Derviş Karaboğa from the University of Erciyes. The general flow diagram is given in Figure 6 (Adebiyi et al., 2017). 


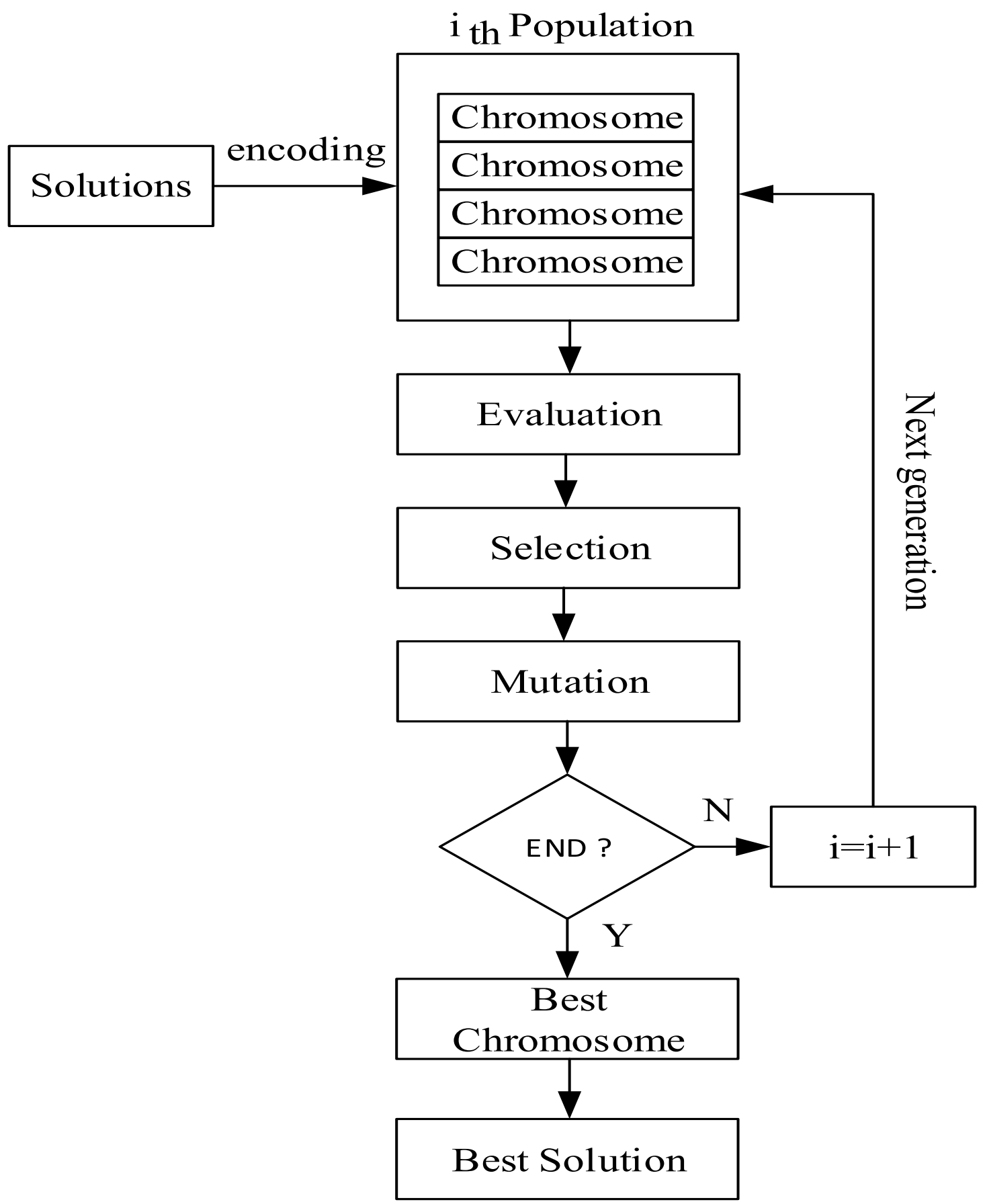

Figure 5. The flowchart of GA. 


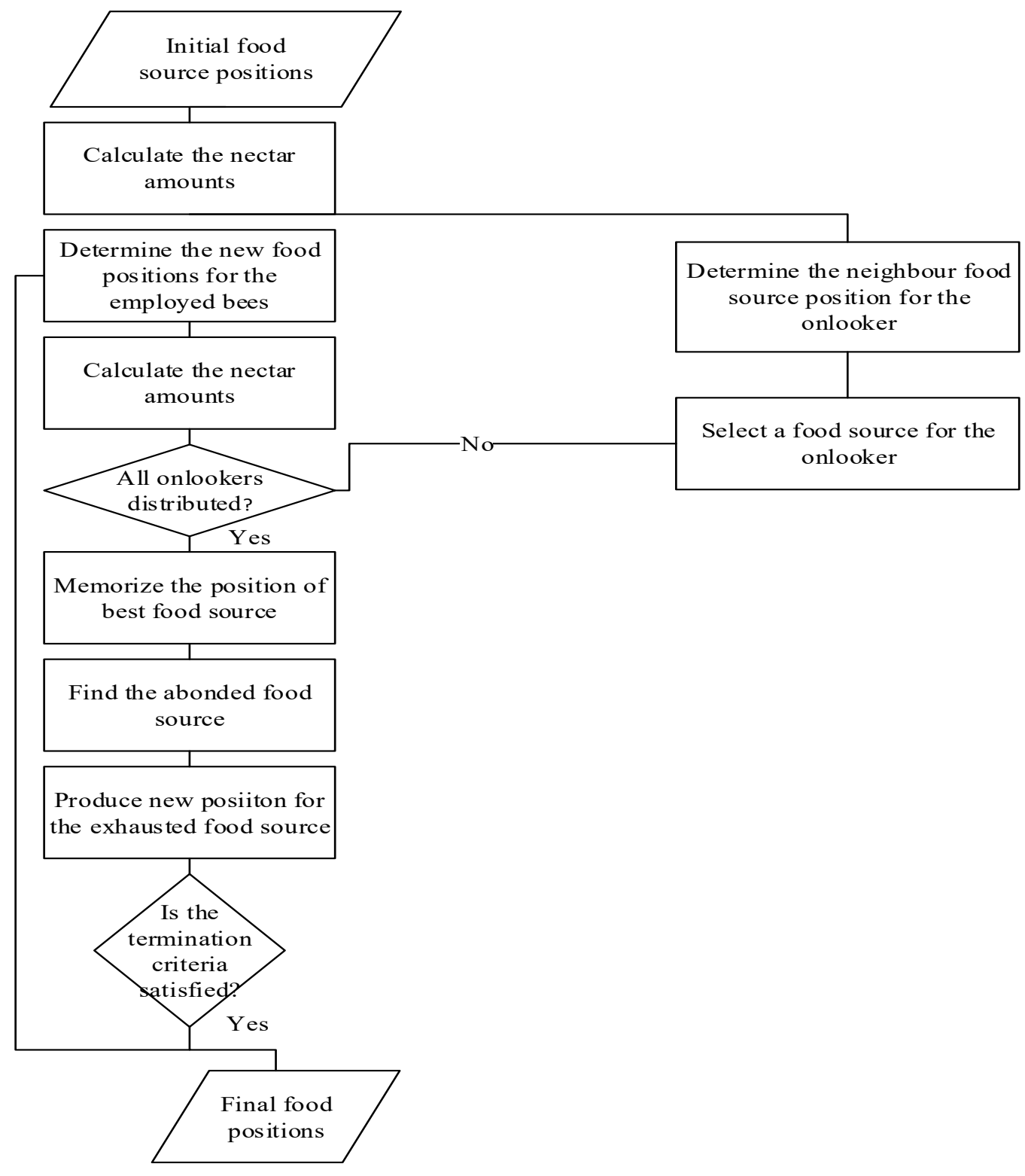

Figure 6. The flowchart of $A B C$.

\section{SIMULATION and RESULTS}

\section{Description of the Line}

In this paper, the effectiveness and performance of the proposed method have been evaluated on a real line. For this purpose, the Ankaray subway line in Turkey has been used. The vast majority of the line is in the tunnels. Therefore, the slope of the track is taken as $0.15 \%$ (Ego, 2019). The line lengths between the stations and the speed limits in the line are given in Table 1. 
Table 1. The lengths and speed limits between stations.

\begin{tabular}{|l|c|c|}
\hline Stations & Length (m) & Speed limit (m/sec) \\
\hline Aşti-Emek & 608 & - \\
\hline Emek-Bahçelievler & 869 & - \\
\hline Bahçelievler-Beşevler & 798 & - \\
\hline Beşevler-Anadolu & 804 & - \\
\hline Anadolu-Maltepe & 531 & $18(350 \mathrm{~m}-500 \mathrm{~m})$ \\
\hline Maltepe-Demirtepe & 946 & - \\
\hline Demirtepe-Milli Irade & 715 & - \\
\hline Mili İrade-Kolej & 977 & $15(450 \mathrm{~m}-600 \mathrm{~m})$ \\
\hline Kolej-Kurtuluş & 551 & \\
\hline Kurtuluş-Dikimevi & 950 & \\
\hline
\end{tabular}

The vehicle used in this subway line belongs to AEG and Breda 94. The parameters of the vehicle are given in Table 2.

Table 2. The parameters of the subway vehicle.

\begin{tabular}{|c|c|}
\hline Parameters & Value \\
\hline Vehicle mass & $40500.0 \mathrm{~kg}$ \\
\hline Maximum speed & $22.2 \mathrm{~m} / \mathrm{sec}$ \\
\hline Maximum acceleration & $1.10 \mathrm{~m} / \mathrm{sec}^{\wedge} 2$ \\
\hline Maximum braking & $1.35 \mathrm{~m} / \mathrm{sec}^{\wedge} 2$ \\
\hline The rated voltage & $750 \mathrm{VDC}$ \\
\hline
\end{tabular}

Ankaray metro line can carry 27000 people/hour in one direction. The busiest stations in terms of passenger numbers are Kızılay, Tandoğan, and Bahçeli stations. The weight of each passenger is included in the calculations over an average of $60 \mathrm{~kg}$.

\section{The Investigation of Actual Driving}

Firstly, the actual driving style has been modeled with DSS in Matlab for comparison ODM. In actual driving style, if there is no restriction on the line, the subway vehicle accelerates up to maximum speed value, continues at a 
constant speed, brakes taking into account the braking distance, and stops at the station point. The actual driving results are given in Table 3.

Table 1. The results of actual driving.

\begin{tabular}{|c|c|c|}
\hline Stations & Travel time (sec) & Energy Consumption (kJ) \\
\hline Aşti-Emek & 55.62 & 13140.8985 \\
\hline Emek-Bahçelievler & 58.55 & 14564.7536 \\
\hline Bahçelievler-Beşevler & 55.48 & 14609.7174 \\
\hline Beşevler-Anadolu & 55.78 & 12563.0298 \\
\hline Anadolu-Maltepe & 43.15 & 15675.5271 \\
\hline Maltepe-Demirtepe & 61.93 & 13494.3104 \\
\hline Demirtepe-Milli Irade & 53.77 & 15908.9730 \\
\hline Mili İrade-Kolej & 63.20 & 12712.9093 \\
\hline Kolej-Kurtuluş & 44.08 & 18587.0788 \\
\hline Kurtuluş-Dikimevi & 68.84 & 146354.8563 \\
\hline Total & 560.4 & \\
\hline
\end{tabular}

As can be seen from Table 3, it takes 560.4 seconds for the subway vehicle to travel from the start station (Aşti) to the end station (Dikimevi) with the actual driving. The amount of energy consumed for this driving is about 146.354 MJ. The energy consumption for all services performed by the subway vehicle within a year is approximately $93.49 * 10^{5} \mathrm{MJ}$.

\section{The Investigation of ODM}

The driving style of a subway vehicle has a major impact on energy consumption. For this reason, the velocity trajectory of the subway vehicle has been optimized to reduce energy consumption by considering all conditions and travel time. As a contribution to the literature, instead of examining the effect of different travel times on energy consumption, energy consumption value has been tried to reduce based on the actual travel time using different force values. Moreover, since there is no energy consumption in this regime, the coasting regime has generally been preferred for ODM. The coasting regime can not be used between short-distance stations (Aşti-Emek/Kolej-Kurtuluş) because the subway vehicle must reach a certain speed in order to go with coasting regime. However, the subway vehicle reaches the braking distance without reaching a certain speed between short-distance stations, so it switches to direct braking after accelerating. Apart from these, the cruising regime has been used for distances with the speed limit. The GA and ABC have been applied to the whole line of the Ankaray subway using all parameters. The travel time and energy consumption results have been found by using the ODM driving technique for both algorithms. The results are given in Table 4. 
Table 4. The results of ODM.

\begin{tabular}{|c|c|c|c|c|}
\hline Stations & \multicolumn{2}{|c|}{ GA } & \multicolumn{2}{c|}{ ABC } \\
\hline & $\begin{array}{c}\text { Travel Time } \\
(\mathrm{sec})\end{array}$ & $\begin{array}{c}\text { Energy } \\
\text { Consumption } \\
(\mathrm{kJ})\end{array}$ & $\begin{array}{c}\text { Travel Time } \\
(\mathrm{sec})\end{array}$ & $\begin{array}{c}\text { Energy } \\
\text { Consumption } \\
(\mathrm{kJ})\end{array}$ \\
\hline Aşti-Emek & 56.65 & 11706.517 & 55.85 & 11849.1997 \\
\hline Emek-Bahçelievler & 63.98 & 13501.2746 & 61.02 & 13819.3191 \\
\hline Bahçelievler-Beşevler & 60.72 & 13272.9913 & 58.21 & 13381.418 \\
\hline Beşevler-Anadolu & 60.92 & 13395.8412 & 57.96 & 13767.9243 \\
\hline Anadolu-Maltepe & 45.27 & 11405.7576 & 44.88 & 11764.2515 \\
\hline Maltepe-Demirtepe & 65.39 & 13882.6263 & 65.64 & 13832.0684 \\
\hline Demirtepe-Milli Irade & 57.1 & 12629.8226 & 55.53 & 13441.7837 \\
\hline Milli Irade-Kolej & 66.97 & 14159.2923 & 67.29 & 13885.3342 \\
\hline Kolej-Kurtulus & 46.06 & 11654.3624 & 45.88 & 11699.1103 \\
\hline Total Line & 595.9 & 131038.091 & 584.15 & 133303.5693 \\
\hline Kurtulus-Dikimevi & 72.84 & 15429.6053 & 71.89 & 15863.1601 \\
\hline
\end{tabular}

As can be seen from Table 4, while the travel time is $595.9 \mathrm{sec}$ in GA, it is $584.15 \mathrm{sec}$ in ABC. The corresponding energy consumption amount is about $131 \mathrm{MJ}$ and $133 \mathrm{MJ}$ for $\mathrm{GA}$ and $\mathrm{ABC}$, respectively. Considering the service amount of the line in one year, the energy consumption amount has been calculated as $83.70 * 105 \mathrm{MJ}$ in GA, and $85.14 * 105 \mathrm{MJ}$ in $\mathrm{ABC}$, while the total energy saving rate is equal to $10,47 \%$ with GA optimization, $8,92 \%$ with $\mathrm{ABC}$ optimization. Although the GA optimization seems to have made a higher saving, ABC optimization is better when both travel time and energy savings are considered because, considering that the increase in travel times is the same, for example, it is calculated that the saving method increased to $12.57 \%$ with a delay of 33.46 seconds in the $\mathrm{ABC}$ method. The velocity-time, distance-time, and energy-time comparisons of driving between two sample stations are shown in Figure 7. 

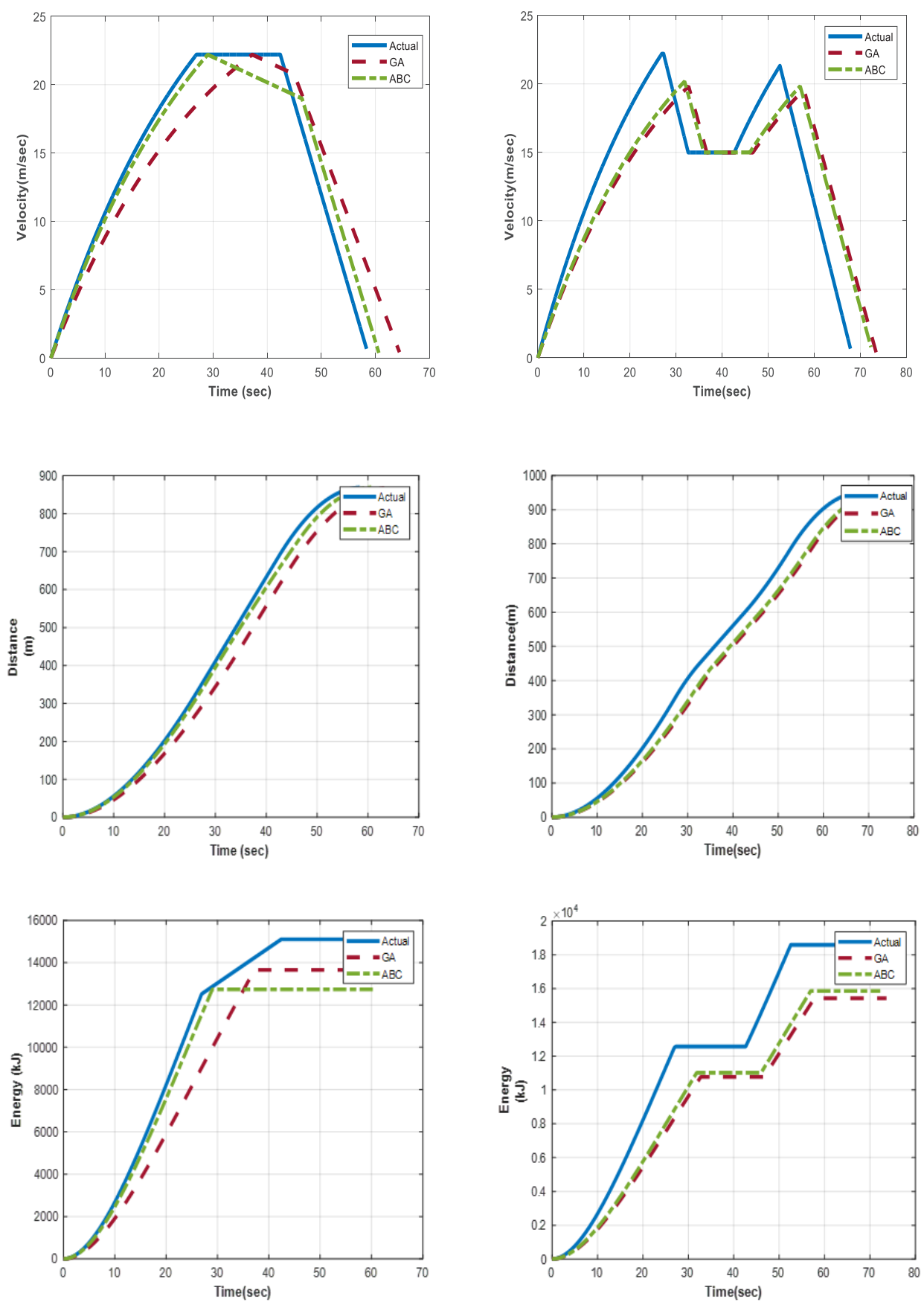

(a)

(b)

Figure 7. The velocity time, distance time, and energy time for two sample station, (a) Emek-Bahçelievler, (b) Kurtuluş-Dikimevi. 


\section{CONCLUSION}

Today, energy efficiency has become a necessity due to various reasons, such as an increase in energy demand, a decrease in energy resources, and global warming. Due to the high energy consumption of subway systems, energy efficiency is vitally important in these systems. The most practical method in these systems is to optimize the driving style and to use efficient driving methods. Therefore, in this paper, the driving of a subway vehicle has been examined and modeled, considering all operation conditions. A method (ODM) has been proposed to reduce the energy consumption of the vehicle considering the actual travel time. The method has been tested in a real line by using GA and $\mathrm{ABC}$ optimization methods. When the proposed method is compared to actual driving, the effects on energy consumption, cost, and emissions have been investigated, and it is successful. The positive aspects of the paper are the real-time reduction of energy consumption, the examination of energy consumption in terms of cost and emission, and the fact that $\mathrm{ABC}$ gives better results than GA, which gives good results in the literature. Also, the study has been designed to be easily tested on other lines.

\section{REFERENCES}

Adebiyi, B.H., Mua'zu, M.B., Tekanyi, A.M.S, Salawudeen, A.T.\& Adebiyi, R.F. 2017. Knowledge-based artificial bee colony algorithm for optimization problems. Journal of Engineering Research. 22(2): 1-13.

Arge, 2019. Üretilen birim güç fiyatina eşdeğer karbondioksit salınımı', https://arge7.com/detay.asp?id=2648, accessed 17 May 2019

Brenna, M., Foiadelli, F. \& Longo, M. 2016. Application of genetic algorithms for driverless subway train energy optimization. International Journal of Vehicular Technology 2: 1-14.

Bigharaz, M.H., Afshar, A., Suratgar, A. \& Safaei, F. 2014. Simultaneous optimization of energy consumption and train performances in electric railway systems. Procedings of Int. Federation of Automatic Control, Cape Town, South Africa. 47(3): 6270-6275.

Davis, V.J. 1926. Tractive resistance of electric locomotives and cars. General/Electric Review 29: 685-708

Ego, 2019. Istatistikler https://www.ego.gov.tr/dosya/indir/16413.pdf, accessed 15 May 2019.

Ghaviha, N., Bohlin, M., Wallin, F. \& Dahlquist, E. 2015. Optimal control of an EMU using dynamic programming. Energy Procedia 75: 1913-1919.

Enerji Atlası. 2019. Enerji Fiyatları. https://www.enerjiatlasi.com/elektrik-fiyatlari, accessed 15 May 2019.

Haramina, H., Mandic, M., Niksic, M. 2012. New method for energy-efficient train operation on commuter rail networks. Tehnicki Viesnik. 19 (4): 801-806.

Hermawanto, D. 2013. Genetic algorithm for solving simple mathematical equality problem. https://arxiv.org/ftp/arxiv/papers/1308/1308.4675.pdf, Accessed on: Apr., 15,2019, accessed 15 Apr. 2019.

Hoang, H., Polis, M.E. \& Haurie, A. 1975. Reducing energy consumption through trajectory optimization for metro network. IEEE Transactions Automatic Control. 20 (5): 590-595.

Kang, M. 2014. A GA based algorithm for creating an energy optimum train speed trajectory. Journal of International Council on Electrical Engineering. 1(2): 123-128.

Liu, R. \& Golovitcher, I.M. 2003. Energy-efficient operation of rail vehicles. Transporation Research Part A: Policy and Practice. 37(10): 917-932.

Liu, H. \& Zhou, M. 2018. An ABC-based subway timetable optimization model for regenerative energy utilization. Procedings of Int. Conf. on Systems, Man and Cybernetics.

Lu, S. 2011. Optimizing power management strategies for railway traction systems. Ph.D. thesis, Birmingham University. 
Mandic, M., Uglesic, J. \& Milardic, V. 2011. Method for optimization of energy consumption of electrical trains. International Review of Electrical Engineering. 6(1): 292-299.

Miyateke, M. \& Ko, H. 2010. Optimization of train speed profile for minimum energy consumption. IEEJ Transactions on Electrical and Electronic Engineering 5: 263-296.

Montrone, T., Pellegrini, P. \& Nobili, P. 2017. Energy consumption minimization problem in a railway network Transportation Research Procedia 22: 85-94.

Müsiad, 2017. Metro İstanbul Enerjı Görünümü ve Yönetimi. http://www.musiad.org.tr/F/Root/Metro-istanbulas.pdf, accessed 9 May 2019.

Rocha, A., Araujo, A., Carvalho, A., Sepulveda, J. 2018. A new approach for real-time train energy efficiency optimization. Energies 11: 1-21.

Su, S., Li, X., Tang, T. \& Gao, Z. 2013. A subway train timetable optimization approach based on energyefficient operation strategy. IEEE Transactions on Intelligent Transport Systems. 14 (2): 883-893

Yang, L., Li, K., Gao, Z. \& Li, X. 2012. Optimizing trains movement on a railway network. Omega. 40 (5): 619 633. 